\title{
Comparative Study of Serum Gamma Glutamyltransferase, 5' Nucleotidase and Alkaline Phosphatase in Icteric and an-Icteric Biliary Disease Patients
}

Gill MPS

Department of General Surgery, Dr. Harvansh Singh Judge Institute of Dental Sciences and Multispecialty Hospital, Panjab University, INDIA.

\begin{abstract}
Introduction: Diagnostic enzymology plays a useful role in evaluation of various hepatobiliary diseases and numerous enzymes have been compared in different disorders. Among these, significance of Gamma Glutamyl Transferase and 5' Nucleotidase over Alkaline Phosphatase has been stressed repeatedly, but mainly in the icteric obstructive biliary disease patients. In this study, these three enzymes were compared not only in the icteric but also the an-icteric biliary disease patients, particularly to look for elevation and significance of these enzymes in the latter group. Methods: The study was conducted on 50 biliary disease patients, who were further divided into an-icteric ( 32 patients) and icteric (18 patients) subgroups depending on their bilirubin levels. 50 subjects matched for age and sex with the study group were enrolled for the control group. Gamma Glutamyl Transferase, 5’Nucleotidase, Alkaline Phosphatase and bilirubin levels were evaluated in all the patients as well as the control subjects. Results: All three enzymes showed a significant rise in the icteric subgroup ( $p$ value < 0.001). However, in the an-icteric subgroup, only Gamma Glutamyl Transferase and 5'Nucleotidase showed a significant rise. The rise was more for Gamma Glutamyl Transferse (1.60 times normal, $p$ $<0.001)$ as compared to 5'Nucleotidase (1.39 times normal, $p<0.01)$. Conclusion: Gamma Glutamyl Transferase and 5'Nucleotidase are useful for evaluation of not only obstructive biliary disease patients but also for the patients with biliary disease who are an-icteric, and out of these two, the former is a more valuable diagnostic indicator in such diseases.
\end{abstract}

KEYWORDS: Gamma Glutamyltransferase; 5' Nucleotidase; Alkaline Phosphatase; icterus, biliary diseases

\section{INTRODUCTION}

Diagnostic enzymology measures the serum or plasma levels of enzymes that are originally located within the cell or are attached to its plasma membrane with their active sites exposed to the external milieu. Shedding of hepatocyte plasma membrane is thought to be responsible for the release of liver plasma membrane fragments in the circulation in various hepatobiliary diseases. Several membrane-bound enzymes such as Gamma Glutamyl Transferase (GGT), Alkaline Phosphatase (ALP), Leucine Aminopeptidase and 5' Nucleotidase (5'NT) are expressed on the surface of these shed liver plasma membrane fragments, ${ }^{1}$ resulting in raised serum levels of these enzymes in various disorders.

Liver having a significant reserve and regenerative powers, and gallbladder acting as a reservoir of bile, pose a limitation in singling out an enzyme or a metabolite which is specific to this organ-system and is an early indicator of its disorders. So many often a battery of tests is required to reach a conclusion.

Corresponding author:

Dr. Maninder Pal Singh Gill

H. No. 1658 ,

Phase 7 ,

SAS Nagar, Mohali,

Punjab, INDIA 160062

Phone: +919815173689

E-mail: manindergill2809@yahoo.com
The three enzymes - Alkaline Phosphatase, 5' Nucleotidase and Gamma Glutamyl Transferase show elevation in hepatobiliary diseases, particularly those affecting the biliary tract. The elevation of these three enzymes correlates closely, although GGT is generally increased to a greater extent as compared to the other two enzymes, ${ }^{2-4}$ thereby indicating the greater sensitivity of GGT as compared to the other two.

These enzymes have been compared with each other as well as with other indicators of biliary tract disease and hepatic parenchymal cell damage. The significance of GGT and 5' NT over ALP has been stressed particularly in obstructive biliary disease patients with icterus. ${ }^{2-5}$ However, in this study these three enzymes have been compared not only in biliary tract disease patients with icterus, but also in those which showed no rise in bilirubin i.e. were an-icteric, particularly to see for the pattern of elevation and significance if any, of these enzymes in the latter group, i.e. an-icteric biliary disease patients.

\section{MATERIALS AND METHODS}

50 patients suffering from various biliary diseases were enrolled for the study. A detailed history was taken, complete physical examination conducted and the required investigations, including an ultrasound abdomen were done to confirm the diagnosis.

$10 \mathrm{ml}$ of venous blood was taken for analyzing GGT, 5'NT, ALP and bilirubin levels. The values were measured in serum, after allowing the sample to clot and then centrifuging at $3000 \mathrm{rpm}$ for 10 minutes to separate the serum.

GGT was measured by the method of Szasz and Klin. ${ }^{6} 5^{\prime} \mathrm{NT}$ was measured by the method of Campbell ${ }^{7}$ and ALP by the method of Kind and King. ${ }^{8}$ 
50 healthy controls matched for age and sex were enrolled in the control group, and it was ensured that none had any hepatobiliary disorder (previously or present), coronary artery disease, diabetes or prolonged drug therapy. The mean values of the three enzymes in this group were taken as normal.

Bilirubin levels of below $1 \mathrm{mg} / \mathrm{dL}$ were taken as normal and such patients were considered an-icteric, whereas patients with levels more than this were considered icteric.
The study was cleared by the research and ethics committee of the institute where the work was carried out and the patients/subjects signed an informed consent regarding participation in the study.

\section{RESULTS}

The 50 patients comprising the study group had an average age of 48 years, with a range of 16 to 70 years. The group had 29 (58\%) females and 21 (42\%) males. The control group had 50 healthy subjects with a comparable age and sex distribution.

Table I. Mean values and rise (as times normal) of serum levels of GGT, 5'NT and ALP in different groups

\begin{tabular}{lllllll}
\hline & \multicolumn{2}{c}{ GGT } & & 5'NT & ALP & \\
\cline { 2 - 7 } & $\begin{array}{l}\text { Mean value } \\
\text { (Szasz units) }\end{array}$ & $\begin{array}{l}\text { Rise as } \\
\text { times normal }\end{array}$ & $\begin{array}{l}\text { Mean value } \\
\text { (IU/L) }\end{array}$ & $\begin{array}{l}\text { Rise as } \\
\text { times } \\
\text { normal }\end{array}$ & $\begin{array}{l}\text { Mean value } \\
\text { (KA units) }\end{array}$ & $\begin{array}{l}\text { Rise as } \\
\text { times } \\
\text { normal }\end{array}$ \\
\hline $\begin{array}{l}\text { Control Group } \\
\begin{array}{l}\text { Study Group } \\
\text { (50 patients) }\end{array}\end{array}$ & 22.54 & - & 9.18 & - & 7.10 & - \\
$\begin{array}{l}\text { An-icteric Subgroup } \\
\text { (32 patients) }\end{array}$ & 36.94 & 2.88 & 18.20 & 1.98 & 11.60 & 1.63 \\
$\begin{array}{l}\text { Icteric Subgroup } \\
\text { (18 patients) }\end{array}$ & 116.33 & 1.60 & 12.75 & 1.39 & 8.81 & 1.24 \\
\hline
\end{tabular}

In the control group the mean value of the three enzymes GGT, 5'NT and ALP were 22.54 Szasz units, 9.18 IU/L and 7.1 KA units respectively, which is within the reported normal range for each enzyme (Table I). Further, in the control group, the enzymes did not show any particular trend with age and also there was no variation among males and females.

The various biliary tract diseases among the study group patients included cholecystitis with cholelithiasis (62\%), choledocholithiasis $(28 \%)$, carcinoma gall bladder $(6 \%)$ and miscellaneous group comprising of peri-ampullary carcinoma and carcinoma head pancreas (4\%). These patients were further divided into two subgroups i.e an-icteric and icteric subgroup depending on their bilirubin levels. Out of the total 50 patients, there were 32 patients with normal bilirubin levels forming the an-icteric group and this group showed a mean bilirubin value of $0.75 \mathrm{mg} /$ dL. 18 patients with elevated bilirubin levels formed the icteric group with an average bilirubin level of $4.95 \mathrm{mg} / \mathrm{dL}$.

Mean values of all the three enzymes i.e. GGT, 5'NT and ALP showed a rise in the study group as a whole, as well as the two subgroups. Table I shows the mean values of the three enzymes in various groups as well as the rise as times normal in the study group and an-icteric and icteric subgroups.

Among the three enzymes, the rise was highest for GGT and least for ALP in the study group as well as both the an-icteric and icteric subgroups. The elevation in the mean values of enzymes was further evaluated statistically for significance in all the different groups. Table II shows the significance/ insignificance of the rise in the levels of different enzymes in various groups at different "p" values.

Table II. Significance (+)/insignificance (--) of rise in the levels of GGT, 5'NT and ALP in various groups at $p<0.01$ and $p<$ 0.001

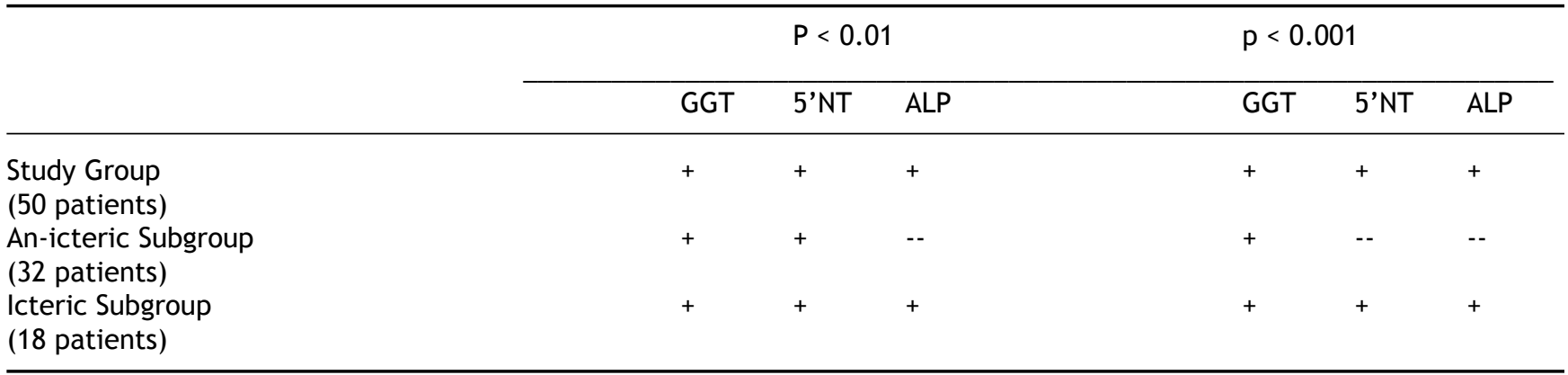


In the icteric subgroup, the rise in all the three enzymes was highly significant ( $p$ value $<0.001$ ). However, in the an-icteric subgroup the rise was significant only for GGT and 5'NT ( $p<$ 0.001 for GGT and $p<0.01$ for 5 'NT) and not for ALP $(p>0.01)$.

\section{DISCUSSION}

In obstructive biliary diseases, usefulness of GGT over ALP has been demonstrated by various authors. ${ }^{2,3,4,9}$ GGT is more responsive to biliary obstruction than are other liver enzymes too, like Aspartate Aminotransferase (AST) and Alanine Aminotransferase (ALP), and being more specific it is helpful in working up elevated levels of ALP. ${ }^{9}$ Similarly 5'NT also shows a much higher elevation as compared to ALP in obstructive jaundice making it a more reliable diagnostic test in this condition. ${ }^{5}$ Among GGT and 5'NT, GGT shows a higher elevation in patients with cholestasis, which is even more marked in extrahepatic cholestasis. $^{3}$ In the present study, the icteric subgroup which comprised of obstructive biliary disease patients reflected the same findings. Although all three enzymes were significantly elevated, the rise was maximal for GGT, followed by 5'NT and least for ALP. This confirms GGT as a valuable diagnostic aid for the investigation of obstructive biliary disease patients.

The an-icteric subgroup which comprised largely of patients of chronic cholecystitis with cholelithiasis also showed a rise in the mean levels of all three enzymes, although it was much less than the icteric subgroup. Further, this rise was significant only for GGT and 5'NT and not for ALP. Among GGT and 5'NT, the rise was more significant in the former ( $p<0.001$ for GGT and $p<0.01$ for 5 'NT).

Lum and Gambino, ${ }^{10}$ reported that in cases of cholecystitis or cholelithiasis, GGT was not only more sensitive than ALP, its rise also preceded that of ALP. However, they suggested this in cases associated with biliary tract obstruction and reported normal GGT levels in cases of cholecystitis without biliary obstruction. Boone et al. ${ }^{11}$ reported increased GGT levels in the majority of their cases of cholecystitis. However, Singh et al. ${ }^{4}$ reported normal GGT levels in patients of cholecystitis and cholelithiasis. Similarly, Jimenez et al. ${ }^{12}$ although measured salivary GGT, reported normal GGT levels in cases of silent cholelithiasis and increased levels in acute cholecystitis.

Yang et al. ${ }^{13}$ while reporting biochemical predictors for bile duct stones emphasized that GGT is the most powerful independent predictor for this condition. Further, GGT has the highest negative predicting value among the biochemical markers like GGT, ALP, AST/ALT and Bilirubin. Ahmad, ${ }^{14}$ while comparing Liver Function Tests before and after surgery in patients of cholelithiasis, also reported highest increase for GGT (upto > $200 \%$ ) as compared to ALP or bilirubin. This indicates the usefulness of GGT even when the other enzymes and bilirubin may not show a significant rise in their levels.

In this study, the GGT levels were significantly elevated in the an-icteric subgroup indicating the usefulness of this enzyme in such conditions also, apart from the patients with jaundice i.e. obstructive biliary diseases. The rise might be attributed to inflammatory edema, which causes some degree of obstruction, which although does not cause any rise in the bilirubin levels but is reflected in the raised GGT levels.

Serum 5'NT activity is generally elevated in hepatobiliary diseases, especially with intrahepatic obstruction, but, unlike serum ALP, serum $5^{\prime} N T$ activity is not increased in infancy, childhood, pregnancy, or osteoblastic disorders. ${ }^{15}$ This makes 5'NT more useful as compared to ALP for evaluation of obstructive biliary diseases. This advantage coupled with the fact that 5'NT has shown a significant rise in an-icteric biliary disease patients and ALP has not shown any such significant rise, shows the usefulness and superiority of this enzyme over ALP as a diagnostic tool in evaluation of such biliary disease patients.

\section{CONCLUSION}

To conclude, GGT and 5'NT are useful for evaluation of not only obstructive biliary disease patients, but also for the patients with biliary disease who are an-icteric. Further they score over ALP, both for patients with or without biliary obstruction. Among GGT and 5'NT, former has got a better diagnostic relevance in evaluation of biliary disease patients.

\section{CONFLICT OF INTEREST}

Authors declare that there is no conflict of interest.

\section{ACKNOWLEDGEMENT}

I would like to thank Dr. Kiranjeet Kaur, Ex - Head of Department, Biochemistry, Government Medical College, Patiala (Punjab) for her valuable advice and help in carrying out this study.

\section{REFERENCES}

1. Van Hoof VO, Deng JT, De Broe ME. How do plasma membranes reach the circulation? Clin Chim Acta 1997; 266:23-31.

2. Whitfield JB, Pounder RE, Neale G, Moss DW. Serum GGT activity in liver disease. Gut 1972; 13:702-8.

3. Sapey T, Mendler MH, Guyader D, et al. Respective value of alkaline phosphatase, gamma-glutamyl transpeptidase and 5' nucleotidase serum activity in the diagnosis of cholestasis: a prospective study of 80 patients. J Clin Gastroenterol 2000; 30: 259-63.

4. Singh MK, Tiwary SK, Patil DB, Sharma D, Shukla VK. Gamma-Glutamyl Transpeptidase (GGT) as a marker in obstructive jaundice. The Internet Journal of Surgery 2007; 9(2). DOI:10.5580/102f

5. Raghavendra DS, Rao SB. Studies on some serum enzyme levels in various liver diseases. Indian J Clin Biochem 2000; 15:48-51.

6. Szasz G, Klin MZ. Serum GGT determination. Chem Biochem 1972; 12:228.

7. Campbell DM. Determination of 5'-nucleotidase in blood serum. Biochem J 1962; 82:34.

8. Kind PRN, King EJ. Estimation of plasma phosphatase by determination of hydrolysed phenol with amino-antipyrine. J Clin Pathol 1954; 7:323.

9. Stein TA, Burns GP, Wise L. Diagnostic value of liver function tests in bile duct obstruction. J Surg Res 1989; 46:226-9.

10. Lum G, Gambino SR. Serum GGT Activity as an indicator of disease of liver, pancreas or bone. Clin Chem 1972; 18:358-62.

11. Boone DJ, Routh DJ, Schrantz R. GGT and 5'NT Comparison as diagnostic enzymes for hepatic diseases. Am J Clin Path 1974; 61:322-7. 
12. Jimenez A, Jaimez L, Barrios L, et al. Salivary GGT activity in internal diseases. Arch Intern Med 1984; 144:1804-6.

13. Yang MH, Chen TH, Wang SE, et al. Biochemical predictors for absence of common bile duct stones in patients undergoing laparoscopic cholecystectomy. Surg Endosc 2008; 22:1620-4.

14. Ahmad NZ. Routine testing of liver function before and after elective laparoscopic cholecystectomy: is it necessary? Journal of the Society of Laparoendoscopic Surgeons 2011; 15:65-9.

15. Sunderman FW. The clinical biochemistry of 5'- 